\title{
Soft computing predictions of relative energy dissipation for vertical drops equipped with a horizontal screen
}

\author{
Reza Norouzi ${ }^{1}$, Rasoul Daneshfaraz ${ }^{2}$, John Abraham ${ }^{3}$ and Parveen Sihag ${ }^{4}$ \\ 1 Ph.D., Department of Water Engineering, Faculty of Agriculture, University of Tabriz, Tabriz, Iran. Email: \\ Rezanorouzi1992@tabrizu.ac.ir; ORCID: 0000-0002-3756-8746 \\ 2 Professor, Department of Civil Engineering, Faculty of Engineering, University of Maragheh, Maragheh, \\ East Azerbaijan, Iran. Email: daneshfaraz@maragheh.ac.ir; ORCID: 0000-0003-1012-8342 \\ 3 Professor, School of Engineering, University of St. Thomas, St Paul, MN, USA. Email: \\ jpabraham@stthomas.edu; ORCID: 0000-0002-3818-8681 \\ 4 Assistant Professor, Department of Civil Engineering, Shoolini University, Solan, Himachal Pradesh, India \\ 173229. Email: parveen12sihag@gmail.com; ORCID:0000-0002-7761-0603 \\ * Correspondence: daneshfaraz@maragheh.ac.ir
}

\begin{abstract}
Drops are the most important and most common energy dissipator in irrigation networks and erodible canals and consequently, their performance must be well understood. This study was designed to evaluate the capability of Artificial Intelligence (AI) methods including ANN, ANFIS, GRNN, SVM, GP, MLR, and LR to predict the relative energy dissipation $\left(\Delta E / E_{0}\right)$ in vertical drops equipped with a horizontal screen. For this study, 108 experiments were carried out to investigate energy dissipation with variable discharge, varying drop height, and porosity of the horizontal screens. Parameters $y_{c} / h, y_{d} / y_{c}$, and $p$ are considered as input variables and $\Delta E / E_{0}$ is the output variable. The efficiency of models was compared using Taylor's diagram, Box Plot of the applied error distribution, correlation coefficient (CC), mean absolute error (MAE) and root-mean-square error (RMSE). Results indicate that the performance of the ANFIS_gbellmf based model with CC value of 0.9953 , RMSE value of 0.0069 and MAE value of 0.0042 was superior to other applied models. Also, the linear regression model with $C C=0.9933$, RMSE $=0.0083$, and MAE $=$ 0.0067performs better than the multiple linear regression model in this study. Results of a sensitivity study suggest that $y_{c} / h$ is the most effective parameter for predicting $\Delta E / E 0$.
\end{abstract}

Keywords: Drop; relative energy dissipation; screen; soft computing

\section{Introduction}

Screens are structures that are used to increase energy dissipation and reduce the length of the settling basin[4]. Screens do not replace the settling basin, but they can be used when settling basins are not technically or economically viable. Screens often cause energy dissipation downstream of hydraulic structures by imposing a hydraulic jump and by promoting turbulence. Vertical drops can be used as a kinetic energy reducer. The inlet flow is one of the most important design components and the flow is usually sub-critical. However, supercritical flow is also possible in some situations. Many researchers have carried out extensive experimental and numerical studies to calculate energy dissipation for these devices (Rajaratnam and Hurtig [4]); (Chamani et al. [10]); (Kabiri-Samani et al. ); (Daneshfaraz et al. ).

Rouse [4] was one of the first research studies on this topic; he presented an equation to calculate the discharge by measuring the brink depth. Chamani and Beirami [8] studied the effect of supercritical flow upstream of a vertical drop on the hydraulic parameters. They showed that increasing the Froude number for a constant discharge decreases the relative pool depth, the relative 
downstream depth, and the relative energy dissipation. Balkiş studied the effect of the slope of the screens on the energy dissipation. The results showed that the slope of the screens do not affect the energy dissipation rate. Esen et al. [4] investigated the effect of different dimensional steps downstream of a drop with an upstream subcritical flow. They observed that stairs downstream of a vertical drop increased the relative downstream depth and the relative energy dissipation. Hong et al. [1] studied the influence of downstream slopes on hydraulic parameters of vertical drop. The researchers tested four different slopes downstream of the vertical drop and they indicated that by increasing the slope, the slope length and impact parameters increase.

Sadeghfam et al. [2] studied energy dissipation in a submerged hydraulic jump that employed dual vertical screens. They showed dual vertical screens dissipate more energy by imposing a hydraulic jump formation. Daneshfaraz et al. [10] evaluated screen performance in the dissipation of energy using numerical simulation. The numerical model results were compared with experimental results. Results showed an ability of the numerical simulation to provide solutions with high accuracy. Kabiri-Samani et al. Investigated the behavior of grid drop-type dissipators. Their results revealed that the use of grid drop-type dissipators increased the relative downstream depth of the pool and the relative energy dissipation compared to a vertical drop. Sharif and Kabiri-Samani and (Kabiri-Samani et al. ) investigated the effect of downstream depth on the hydraulic performance of grid drop-type dissipators.

Daneshfaraz et al. [6] Investigated the behaviour of screens in movable-bed channels. They derived a set of equations to describe the dimensions of the scouring pit induced by screens. Using an experimental study, (Daneshfaraz et al. ) investigated the effect of dual horizontal screens on hydraulic behavior. Their results indicated that by using dual horizontal screens, the flow regime can be transformed from supercritical to subcritical downstream of the drop. Machine learning systems have recently been utilized to predict energy dissipation in hydraulic structures. Norouzi et al. Studied the performance of an adaptive neuro-fuzzy inference system (ANFIS) on the energy dissipation of inclined drops equipped with downstream vertical screens. The showed that the ANFIS model values of $\mathrm{R}^{2}$ and RMSE are 0.996 and 0.006 , respectively. ANFIS has an excellent ability to calculate the energy dissipation associated with inclined drops that are equipped with downstream vertical screens. Sadeghfam et al. [5] used artificial intelligence to combine multiple models (AIMMs) for calculating supercritical jet flow upstream of screens. The results showed that the AIMM model has a good capability in modelling scouring dimensions.

Despite this large body of prior work, little research has been done on the performance of an intelligent model for predicting energy dissipation in drops. Therefore, in the present study, independent intelligent models such as Artificial Neural Networks (ANN), Adaptive Neuro-Fuzzy Inference System (ANFIS), Support Vector Machine (SVM), Generalized Regression Neural Network (GRNN), Gaussian Process regression (GP), and both multiple linear and nonlinear regression methods were applied to evaluate energy dissipation in drops and with a horizontal screen. In the present study, the performance of standalone intelligent models was used to estimate the energy dissipation in drops.

\section{Materials and Methods}

\subsection{Experimental Set-up}

Experiments were carried out in a laboratory flume $5 \mathrm{~m}$ in length, $0.3 \mathrm{~m}$ in width and with a variable depth that ranged from $0.45-0.75 \mathrm{~m}$. The test facility was housed in the hydraulic laboratory at the University of Maragheh. Inlet flow was regulated by two pumps, each with a capacity of 450 liters per minute. Flowrate was measured using a rotameter mounted on the pump with $\pm 2 \%$ accuracy. The inlet flow is pumped into the upstream reservoir by the pump and enters the flume bypassing the baffle. Water depths were measured at five points along the channel width with $\mathrm{a} \pm 1$ $\mathrm{mm}$ precision point gauge. The characteristics of the laboratory model made in the present study are presented in Table 1 and shown in Fig. 1. 
Table 1. Specification of the laboratory model

\begin{tabular}{|c|c|c|c|c|c|c|c|}
\hline \multicolumn{4}{|c|}{ Vertical drop } & \multicolumn{4}{|c|}{ Screen } \\
\hline Type & Height (m) & $\begin{array}{c}\text { Width } \\
(\mathrm{m})\end{array}$ & $\begin{array}{c}\text { Length } \\
(\mathrm{m})\end{array}$ & Type & $\begin{array}{c}\text { Porosity } \\
(\%)\end{array}$ & $\begin{array}{c}\text { Thickness } \\
\text { (m) }\end{array}$ & $\begin{array}{c}\text { Length } \\
\text { (m) }\end{array}$ \\
\hline Glass & $\begin{array}{c}0.15-0.2- \\
0.25\end{array}$ & 0.3 & 1.2 & Polyethylene & $40-50$ & 0.01 & 0.7 \\
\hline
\end{tabular}

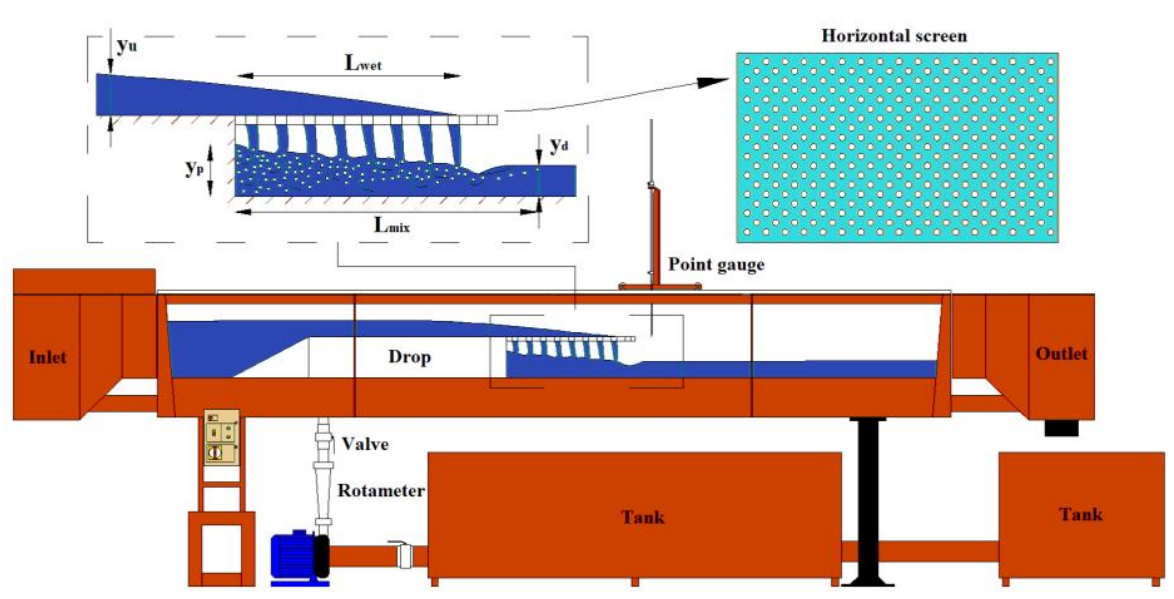

Figure 1. Schematic of the experimental setup and water circulation system

Using the laboratory apparatus just described, 108 experiments were carried out to investigate energy dissipation with varying flow, drop height and porosity of the horizontal screens.

\section{Calculation of energy dissipation}

To calculate the energy upstream of the vertical drop, Eq. (1) from (Bakhmeteff ) was used:

$$
\mathrm{E}_{\mathrm{u}}=1.5 \mathrm{y}_{\mathrm{c}}+\mathrm{h}
$$

where $E_{u}$ is the total energy upstream of the drop, $h$ is the drop height and $y_{c}$ is critical depth upstream of the drop. Equation (2) is used for calculating the energy downstream of the drop.

$$
E_{d}=y_{d}+\frac{q^{2}}{2 g y_{d}^{2}}
$$

In Eq. (2), $E_{d}$ is the total energy downstream of the vertical drop, $y_{d}$ is the downstream depth, $g$ is the acceleration of gravity, and $q$ is the discharge per unit width. Next, Eq. (3) was used to calculate the relative energy dissipation for the vertical drop structures.

$$
\frac{\Delta \mathrm{E}}{\mathrm{E}_{\mathrm{u}}}=\frac{\mathrm{E}_{\mathrm{u}}-\mathrm{E}_{\mathrm{d}}}{\mathrm{E}_{\mathrm{u}}}
$$

\subsection{Dimensional Analysis}

The geometric and hydraulic parameters affecting the flow are given in Eq. (4): 


$$
\mathrm{f}_{1}\left(\mathrm{r}, \mathrm{m}, \mathrm{g}, \mathrm{Q}, \mathrm{h}, \mathrm{p}, \mathrm{t}, \mathrm{y}_{\mathrm{c}}, \mathrm{y}_{\mathrm{u}}, \mathrm{y}_{\mathrm{b}}, \mathrm{y}_{\mathrm{d}}, \mathrm{y}_{\mathrm{p}}, \mathrm{L}_{\text {mix }}, \Delta \mathrm{E}, \mathrm{E}_{\mathrm{u}}\right)=0
$$

where $\rho$ is the water density, $\mu$ is dynamic viscosity, $g$ is the gravitational acceleration, $Q$ is the discharge, $h$ is the drop height, $t$ is the screen thickness, Lmix is mixing length, $p$ is the screen porosity ratio, $y_{c}$ is the critical depth, $y_{u}$ is the upstream drop depth, $y_{d}$ is the downstream depth, $y_{p}$ is the pool depth under the falling jet, $\Delta E$ is the dissipated energy, $y_{b}$ is the drop brink depth, and $E_{u}$ is the total energy upstream of the drop.

By using the $\pi$-Buckingham theory and with repeated parameters $y_{u}, \rho$ and $g$, the following non-dimensional equation is achieved:

$$
\mathrm{f}_{2}\left(\operatorname{Re}_{0}, \mathrm{Fr}_{0}, \frac{\mathrm{h}}{\mathrm{y}_{u}}, \mathrm{p}, \frac{\mathrm{t}}{\mathrm{y}_{u}}, \frac{\mathrm{y}_{\mathrm{c}}}{\mathrm{y}_{u}}, \frac{\mathrm{y}_{\mathrm{b}}}{\mathrm{y}_{u}}, \frac{\mathrm{y}_{\mathrm{d}}}{\mathrm{y}_{u}}, \frac{\mathrm{y}_{\mathrm{p}}}{\mathrm{y}_{u}}, \frac{\mathrm{L}_{\mathrm{mix}}}{\mathrm{y}_{u}}, \frac{\Delta \mathrm{E}}{\mathrm{y}_{u}}, \frac{\mathrm{E}_{0}}{\mathrm{y}_{u}}\right)=0
$$

with some simplification, Eq. (6) is obtained:

$$
\mathrm{f}_{3}\left(\operatorname{Re}_{0}, \mathrm{Fr}_{0}, \mathrm{p}, \frac{\mathrm{t}}{\mathrm{h}}, \frac{\mathrm{y}_{\mathrm{c}}}{\mathrm{h}}, \frac{\mathrm{y}_{\mathrm{b}}}{\mathrm{y}_{\mathrm{c}}}, \frac{\mathrm{y}_{\mathrm{d}}}{\mathrm{y}_{\mathrm{c}}}, \frac{\mathrm{y}_{\mathrm{p}}}{\mathrm{h}}, \frac{\mathrm{L}_{\text {mix }}}{\mathrm{h}}, \frac{\Delta \mathrm{E}}{\mathrm{E}_{0}}\right)=0
$$

Considering that the Reynolds number range is 10000-35000, the flow is fully turbulent and viscous effects can be neglected. The measurement of the upstream depth was performed to determine the Froude number range for subcritical flow and it was observed that in all tests, the Froude number is in the range 0.68-0.84. Therefore, the effect of the upstream Froude number is ignored. Also, previous research on the thickness of screens indicates that it can be ignored as well .

By simplifying and disregarding the unimportant parameters, the dependent parameters were obtained as a function of the independent parameters as shown below.

$$
\frac{\Delta E}{E_{0}}=f_{5}\left(\frac{y_{c}}{h}, p, \frac{y_{d}}{y_{c}}\right)
$$

Since the purpose of this paper is to investigate energy dissipation, Eq. (7) is modified to become the following.

$$
\frac{\Delta \mathrm{E}}{\mathrm{E}_{0}}=\mathrm{f}_{5}\left(\frac{\mathrm{y}_{\mathrm{c}}}{\mathrm{h}}, \mathrm{p}, \frac{\mathrm{y}_{\mathrm{d}}}{\mathrm{y}_{\mathrm{c}}}\right)
$$

In Eq. (7), $\Delta E / E_{0}$ is the relative energy. The terms $p$ and $y_{c} / h$ are the porosity of screens and relative critical depth and are independent parameters. The nondimensional ratio of the relative critical depth is in the range $0.07-0.39$ and the porosity ratio of the screens are equal $40 \%$ or $50 \%$.

\subsection{Artificial neural networks (ANN)}

ANN is a soft computing-based approach and can be used to predict energy dissipation. The ANN model is developed using WEKA software. A trial-and-error method is used to develop the most suitable ANN-based model. The networks are controlled by factors such as momentum coefficients, learning rate, number of hidden layers and neurons. The major drawback of the ANN approach is that it represents knowledge in terms of a weight matrix that is not fully understood. Therefore, usually, it is considered a black-box model. Also, the ANN approach needs to find network parameters such as the number of neurons in hidden layers and the number of hidden layers by a 
trial-and-error method which is very time-consuming. A detailed theoretical description of ANN is available in. The main advantage of ANN is that it is easy to use and that it can approximate any input/output map [7]. Prior research, such as have used ANN to model a monthly pan evaporation process and calculated scour depths. Figure 2 shows the structure of ANN with three layers including input, middle, and output layers.

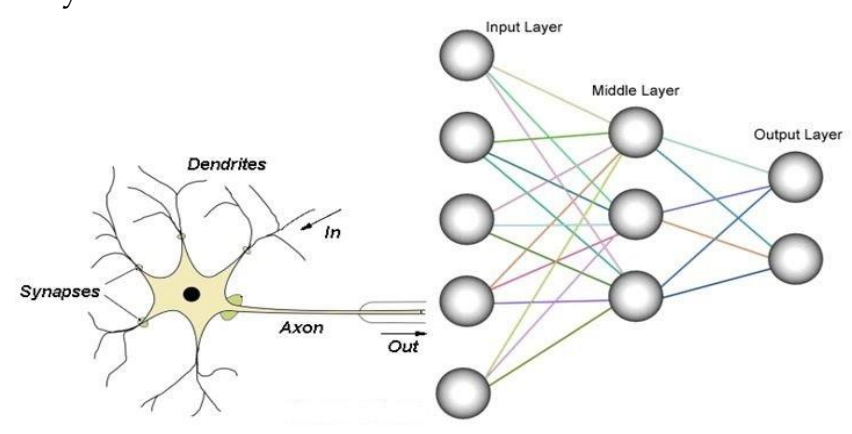

Figure 2. Structure of ANN

\subsection{Adaptive neuro-fuzzy inference system (ANFIS)}

An adaptive network is a multilayer structure whose overall output behavior is determined by the value of a set of modifiable parameters. The adaptive network structure consists of a set of interconnected nodes that are directly connected wherein each node is considered a processing unit. These systems have solved the main problem in fuzzy system design (if-then rules) by making effective use of ANN's automatic production of rule-learning capability and parameter optimization. The two rules of this system are also expressed by Eqs. (9) and (10):

$$
\begin{aligned}
& \text { If } x \text { is } A_{1} \& \text { yis } B_{1} \& z \text { is } C_{1} \\
& \text { Then } f=p_{1} x+q_{1} y+k_{1} z+r_{1} \\
& \text { If } x \text { is } A_{2} \& \text { yis } B_{2} \& z \text { is } C_{2} \\
& \text { Then } f=p_{2} x+q_{2} y+k_{2} z+r_{2}
\end{aligned}
$$

ANFIS is one of the most common fuzzy nervous systems that runs a Sugeno fuzzy system in a neural structure. The system utilizes a combination of backpropagation training and minimum error squares for the training process. With ANFIS, it is necessary to specify the type of membership function and its number in the first layer. For this purpose, in the first layer, there are two methods of network separation and cluster separation for data classification. The types of functions available in this network include Trimf, Gaussmf, Gbellmf, Trapmf. The adaptive neural fuzzy model operates based on the change in the number of center values and the range of belonging functions in different iterations to reach the appropriate network based on the minimum error present. Some of the ANFIS model effectiveness includes the ability to estimate the rectangular side weir discharge capacity , predict side weir discharge coefficient, and study energy decreases of the drop. Figure 3 has been prepared to schematically show the structure of the ANFIS methodology. 


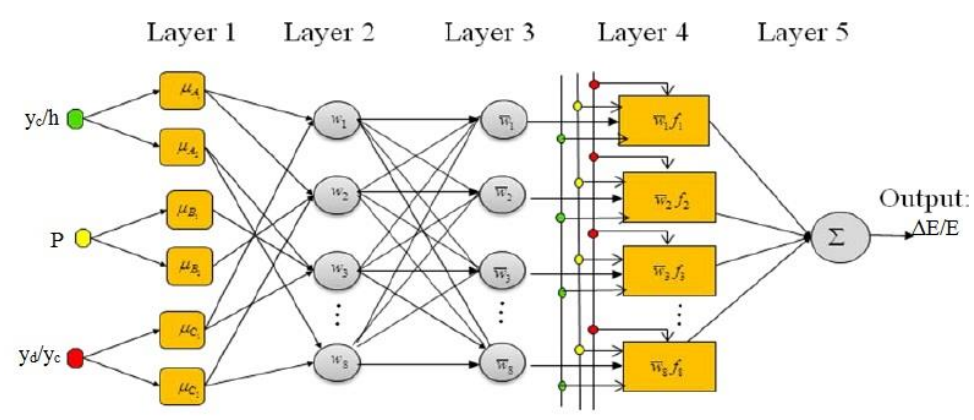

Figure 3. Structure of ANFIS

\subsection{Support vector machine (SVM)}

The SVM algorithm is a classifier that is one of the branches of kernel methods in machine learning. This type of learning system is used to classify and estimate a data fitting function so that minimal error occurs in the data-fitting function. The SVM algorithm was developed by (Vapnik), a Russian mathematician, based on statistical learning theory. The purpose of the support vector machine is to identify a function $f(x)$ for training patterns such that it has the maximum margin of training values $y$. In other words, the SVM is a model that fits a curve of thickness $€$ to the data so that minimal error is observed in the experimental data. In a SVM regression model, it is necessary to estimate the relationship of the dependent variable $y$ to a set of independent variables $x$. It is assumed that, like other regression problems, the relationship between the dependent variables plus a value of independent $f$ is determined by an additional noise function.

$$
y=f(x)+\text { noise }
$$

The key is to find the form of the function $f$ that can correctly predict new quantities that SVM has not experienced before. This function is accessed by training the SVM model on a training dataset. The training includes a process to permanently optimize the error function. Based on the definition of this error function, two well-known models are SVM type regression models, known as SVM-v models and second-order SVM regression models, known as the SVM $-\varepsilon$ models. In this study, the SVM- $\varepsilon$ model was used because of its widespread use in regression problems. For this model, the error function is defined as follows.

$$
\frac{1}{2} W^{T} W+c \sum_{i=1}^{N} \xi_{i}+c \sum_{i=1}^{N} \xi_{i}^{0}
$$

The error function should be minimized using the following constraints.

$$
\begin{aligned}
& W^{T} \Phi\left(x_{i}\right)+b-y \leq \varepsilon+\xi_{i}{ }^{0} \\
& y_{i}-W^{T} \Phi\left(x_{i}\right)-b \leq \varepsilon+\xi_{i}{ }^{0} \\
& \xi_{i}, \xi_{i}{ }^{0} \geq 0 \\
& i=1, \ldots, N
\end{aligned}
$$

where, $C$ is the capacity constant, $W$ is the coefficient vector, $W^{T}$ is the vector of the coefficients, $\xi_{\mathrm{i}}, \xi_{\mathrm{i}}{ }^{0}$ are the deficiency coefficients, $b$ is a constant, $N$ is the training model and $\Phi$ is the kernel function. The radial basis function kernel is the best choice among other kernel functions. In this study, the function defined by $\gamma$ in the following relation is applied. 


$$
K(x i, x)=\exp \left(-\gamma|x i-x|^{2}\right)
$$

Various SVM model results have been used to calculate discharge coefficients modified oblique side weirs . AVM models have also been used to investigate labyrinth and arced labyrinth weir discharge coefficients and to study trapezoidal labyrinth weir discharge coefficients [7].

\subsection{Generalized regression neural network (GRNN)}

A GRNN neural network is a basic radial neural network and a general-purpose approximator for smooth functions. It is capable of smoothly approximating any function provided sufficient data is available. The GRNN is a three-layer neural network in which the number of neurons in the first and the last layer is equal to the dimensions of the input and output vectors. But, unlike other networks, the number of the hidden layer neurons in the GRNN model is equal to the number of observational data. This type of neural network uses the normal efficiency function in each of the hidden layer neurons, and the input data to this function for each neuron is the Euclidean distance between the input data and the observations of that neuron. This calculation is facilitated by Eq. (15).

$$
\begin{aligned}
& \mathrm{f}\left(\mathrm{X}_{\mathrm{r}}, \mathrm{b}\right)=\mathrm{e}^{-\mathrm{I}^{2}} \\
& \mathrm{I}=\left\|\mathrm{X}_{\mathrm{r}}-\mathrm{X}_{\mathrm{b}}\right\| \times 0.836 / \mathrm{h}
\end{aligned}
$$

Here, $X_{r}$ is a vector input to the network with an unknown output, $X_{b}$ is the input value of the observations in time and $b$ and $h$ of the radius range parameter. By changing $h$, the value of the function will be changed so that the function will find the best fit to the data. The output values of this function are in the range $0-1$ so that as the Euclidean distance between the two vectors $X_{r}$ and $X_{b}$ approaches zero, the value of the function approaches one. As the vectors differ, the value of the function approaches zero. The GRNN neural network uses Eq. (16) to calculate the output.

$$
Y_{r}=\frac{1}{\sum_{b=1}^{n} f\left(X_{r}, b\right)} \sum_{b=1}^{n}\left[\mathrm{f}\left(\mathrm{X}_{\mathrm{r}}, \mathrm{b}\right) \times \mathrm{T}_{\mathrm{b}}\right]
$$

where $T_{b}$ is the output value of the observations corresponding to the input vector $b$ and $n$ is the number of observational data. Several prior research studies have used the GRNN method for tasks such as estimating stream water temperature, soil temperature, and GPK Weir discharge coefficients . The structure of the GRNN neural network is shown in Fig. 4.

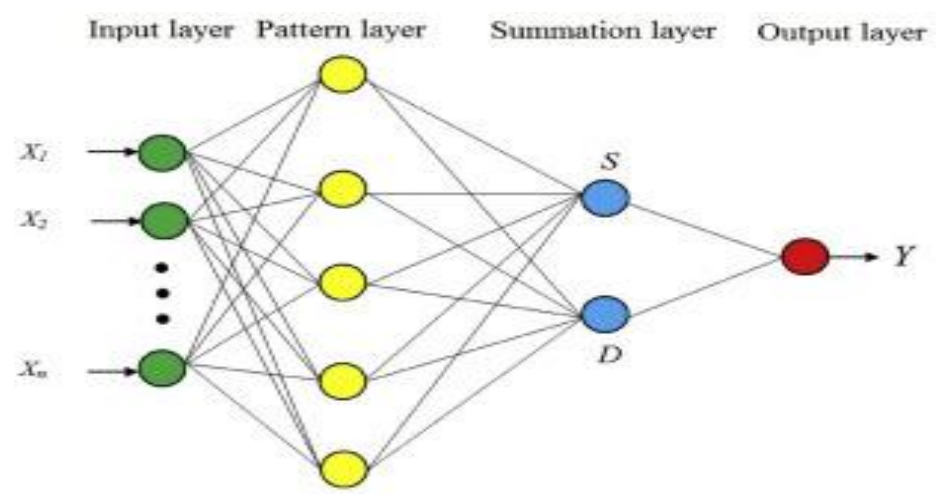

Figure 4. Physical structure of GRNN 


\subsection{Gaussian process model (GP)}

"The Gaussian Process regression model (GP) has increasingly become a statistic tool for datadriven modeling. GP methods are non-parametric systems that can resolve assortment and regression modeling problems. It has been used for identifying the system, responding to surface modeling, and calibrating spectroscopy analyzers " and group learning. The primary aim of the GP technique was to place a priority directly on the space of functions. A formation of previous data and distribution resulted in a posterior distribution of functions. Several different applications of the GP method include the calculation of water temperature and the determination of weir $C_{d}$.

\subsection{Linear regression $(L R)$}

Regression analysis is a statistical method in which the relationship between two or more independent variables is used to predict the dependent variable response. A multiple linear regression model is expressed as follows:

$$
\mathrm{y}=\sum_{\mathrm{i}=1}^{\mathrm{N}} \mathrm{b}_{\mathrm{i}} \mathrm{X}_{\mathrm{i}}+\mathrm{e}
$$

where $\beta_{i}$ indicates regression coefficients, $X_{i}$ is the independent variable, $\varepsilon$ is eccentricity and $N$ is the number of independent variables. The least-squares method is used to estimate the regression coefficients [12]. LR has been used in prior applications, for example for trapezoidal labyrinth side weir discharge coefficients [5] and evaporation modeling [6]. A schematic diagram showing the algorithm is provided in Fig. 5.

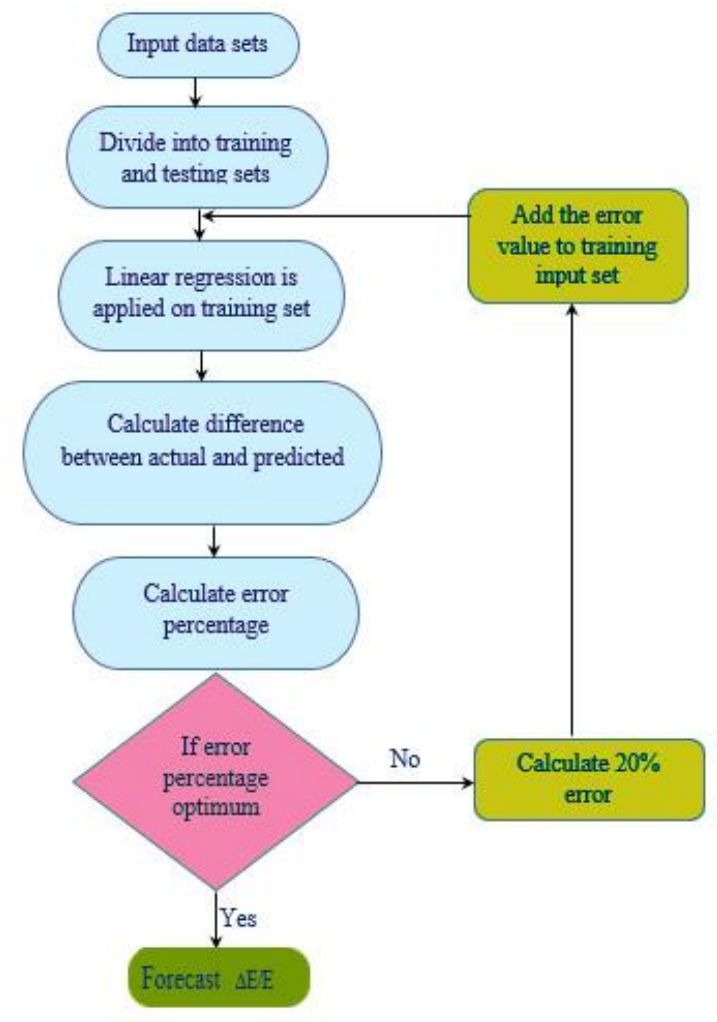

Figure 5. The LR algorithm

\subsection{Multiple linear regression (MLR)}

Multiple non-linear regression (MLR) is applied to more than one of the predictor's parameters. The common structure of the MLR model is: 


$$
\begin{aligned}
& \mathrm{R}=\mathrm{C}_{0} \mathrm{X}_{1}^{\mathrm{C}_{1}} \mathrm{X}_{2} \mathrm{C}_{2} \ldots \ldots \ldots \mathrm{X}_{\mathrm{n}}{ }^{\mathrm{C}_{\mathrm{n}}} \\
& \mathrm{R}=\mathrm{c}_{0} \mathrm{x}_{1}{ }^{\mathrm{c}_{1}} \mathrm{x}_{2}{ }^{\mathrm{c}_{2}} \mathrm{x}_{3}{ }^{\mathrm{c}_{3}} \mathrm{x}_{4}{ }^{\mathrm{c}_{4}} \ldots \ldots \ldots \ldots \ldots \mathrm{x}_{\mathrm{n}}{ }^{\mathrm{c}_{\mathrm{n}}}
\end{aligned}
$$

where $R$ is the dependent variable and $X_{1}, X_{2}, \ldots \ldots$, and $X_{n}$ are independent variables.

\subsection{Performance measures}

Three performance measures, correlation coefficient (CC), mean absolute error (MAE) and rootmean-square error (RMSE), are used to assess the performance of the models. The CC, which ranges from -1 to 1 , is a statistical measure of how well the regression line matches the observed data, and a coefficient of \pm 1 indicates that the regression line perfectly fits the observed data. The RMSE and MAE can provide a balanced evaluation of the goodness of fit of the model as it is more sensitive to larger relative errors that occurs with low values; the perfect model would have a value of zero. These performance measures are calculated by :

$$
\begin{array}{r}
\mathrm{CC}=\frac{\mathrm{n} \sum \mathrm{ab}-\left(\sum \mathrm{a}\right)\left(\sum \mathrm{b}\right)}{\sqrt{\mathrm{n}\left(\sum \mathrm{a}^{2}\right)-\left(\sum \mathrm{a}\right)^{2}} \sqrt{\mathrm{n}\left(\sum \mathrm{b}^{2}\right)-\left(\sum \mathrm{b}\right)^{2}}} \\
\text { MA }=\frac{1}{\mathrm{n}}|\mathrm{a}-\mathrm{b}| \\
\text { RMSE }=\sqrt{\frac{1}{\mathrm{n}} \sum_{\mathrm{i}=1}^{\mathrm{n}}(\mathrm{a}-\mathrm{b})^{2}}
\end{array}
$$

where:

$$
\begin{aligned}
& a=\text { actual values } \\
& b=\text { predicted values } \\
& n=\text { numberofobservations }
\end{aligned}
$$

\section{Data set}

A total of 108 experimental observations were used for this investigation. The dataset was divided into two groups. The larger part (74 observations) was used for the model development and a smaller part (34 observations) was used for validation. The correlation matrix of the total data set is listed in Table 2 and the range and features of both parts are provided in Table 3. The symbols $y_{c} / h$, $y_{d} / y_{c}$, and $p$ are independent variables so these are selected as input variables whereas $\Delta E / E_{0}$ is an output.

Table 2. Correlation matrix of the total data used in this study

\begin{tabular}{ccccc}
\hline Variables & $\mathbf{y c}_{\mathrm{c}} / \mathbf{h}$ & $\mathbf{y d}_{\mathrm{d}} / \mathbf{y}_{\mathbf{c}}$ & $\mathbf{p}$ & $\Delta \mathrm{E} / \mathrm{E}_{0}$ \\
\hline $\mathrm{y}_{\mathrm{c}} / \mathrm{h}$ & 1 & 0.9917 & -0.0953 & -0.9928 \\
$\mathrm{yd}_{\mathrm{d}} \mathrm{yc}$ & 0.9917 & 1 & -0.1332 & -0.9872 \\
$\mathrm{P}$ & -0.0953 & -0.1332 & 1 & 0.0711 \\
$\Delta \mathrm{E} / \mathrm{E}_{0}$ & -0.9928 & -0.9872 & 0.0711 & 1 \\
\hline
\end{tabular}

Table 3. Range and Feature of the data set 


\begin{tabular}{cccccccccc}
\hline \multirow{2}{*}{ Range } & $\mathbf{y}_{\mathbf{c}} / \mathbf{h}$ & $\mathbf{y d} / \mathbf{y}_{\mathbf{c}}$ & $\mathbf{p}$ & $\Delta \mathrm{E} / \mathrm{E}_{0}$ & $\mathbf{y}_{\mathrm{c}} / \mathbf{h}$ & $\mathbf{y d}_{\mathrm{d}} / \mathbf{y}_{\mathbf{c}}$ & $\mathbf{p}$ & $\Delta \mathrm{E} / \mathrm{E}_{0}$ \\
\cline { 2 - 10 } & \multicolumn{5}{c}{ Training data set } & \multicolumn{5}{c}{ Testing data set } \\
\hline Minimum & 0.0768 & 0.0982 & 0.4000 & 0.6321 & 0.1111 & 0.1352 & 0.4000 & 0.6372 \\
Maximum & 0.3743 & 0.4373 & 0.5000 & 0.8909 & 0.3659 & 0.4287 & 0.5000 & 0.8525 \\
Mean & 0.2097 & 0.2413 & 0.4595 & 0.7594 & 0.2270 & 0.2629 & 0.4559 & 0.7471 \\
Standard Deviation & 0.0689 & 0.0849 & 0.0494 & 0.0609 & 0.0785 & 0.0949 & 0.0504 & 0.0680 \\
Skewness & 0.6268 & 0.6358 & -0.3934 & -0.3330 & 0.3857 & 0.3985 & -0.2480 & -0.2800 \\
Confidence Level(95.0\%) & 0.0160 & 0.0197 & 0.0115 & 0.0141 & 0.0274 & 0.0331 & 0.0176 & 0.0237 \\
\hline
\end{tabular}

A Taylor diagram is a visual tool to evaluate the accuracy of estimated data by simultaneously depicting statistical parameters. In this diagram, each point represented the performance of the corresponding method, and the closer the points of the methods to the observational data point in the polar coordinates, the higher the accuracy and the lower the error.

\section{Results and Discussion}

In this study, the modeling methodology involves two stages: training, and testing. This process is used to reduce the generalization error and control overfitting. The suitability of the modeling approach is measured by the statistical measures demonstrated in Table 3 for both modeling stages. The performance of the above-discussed modeling techniques is illustrated in Figs. 6 10. The data predicted with soft computing is plotted against the actual data and represented with the best fit line $(y=x)$ to quantify the scattering.

LR and MLR equations are developed using least square techniques with the help of XLSTAT software. The developed equations are as follow:

$$
\begin{gathered}
\frac{\Delta \mathrm{E}}{\mathrm{E}_{0}}=0.9602-0.6636\left(\frac{\mathrm{y}_{\mathrm{c}}}{\mathrm{h}}\right)-0.1763\left(\frac{\mathrm{y}_{\mathrm{d}}}{\mathrm{y}_{\mathrm{c}}}\right)-0.0416(\mathrm{p}) \\
\frac{\Delta \mathrm{E}}{\mathrm{E}_{0}}=0.5285\left(\frac{\mathrm{y}_{\mathrm{c}}}{\mathrm{h}}\right)^{-0.1111} \times\left(\frac{\mathrm{y}_{\mathrm{d}}}{\mathrm{y}_{\mathrm{c}}}\right)^{-0.1206} \times(\mathrm{p})^{-0.0017}
\end{gathered}
$$

Figure 6 shows the agreement plot of LR and MLR equations. Predicted values using the LR equation are closer to the line of perfect agreement with $\mathrm{R}^{2}$ value as 0.986 . The LR equation is suitable for the prediction of $\triangle E / E_{0}$. Figure 6 and Table 4 indicate that the LR model perroms better than MLR with CC is 0.9933 , RMSE is 0.0083 and MAE is 0.0067. 

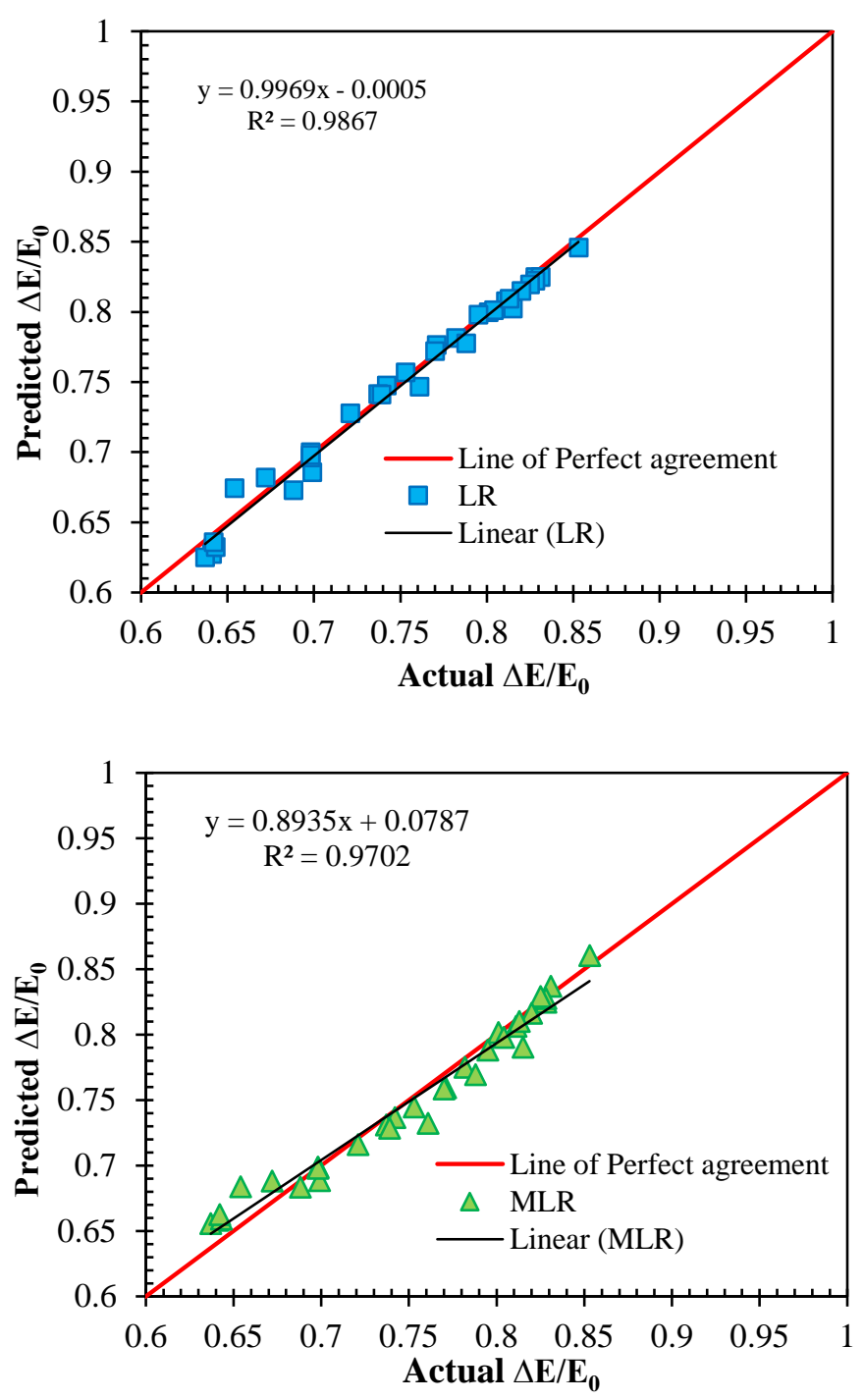

Figure 6. Comparison of actual and predicted values of $\Delta \mathrm{E} / \mathrm{E} 0$ using testing data with (a) LR (b)

\section{MLR}

The preparation of the Gaussian process-based model uses an iterative method. A Pearson VII kernel function and radial basis kernel functions are used for the model preparation. The performance of GP_PUK and GP_RBF models are listed in Table 4. The results suggest that the GP_PUK outperforms the GP_RBF model. Performance evaluation parameters for GP_PUK for the prediction of $\triangle E / E_{0}$ are: $\mathrm{CC}=0.9949, \mathrm{MAE}=0.0040$ and $\mathrm{RMSE}=0.0071$ for the testing stage. Results from the GP_PUK and GP_RBF models during the testing stage are plotted in Fig. 7. 

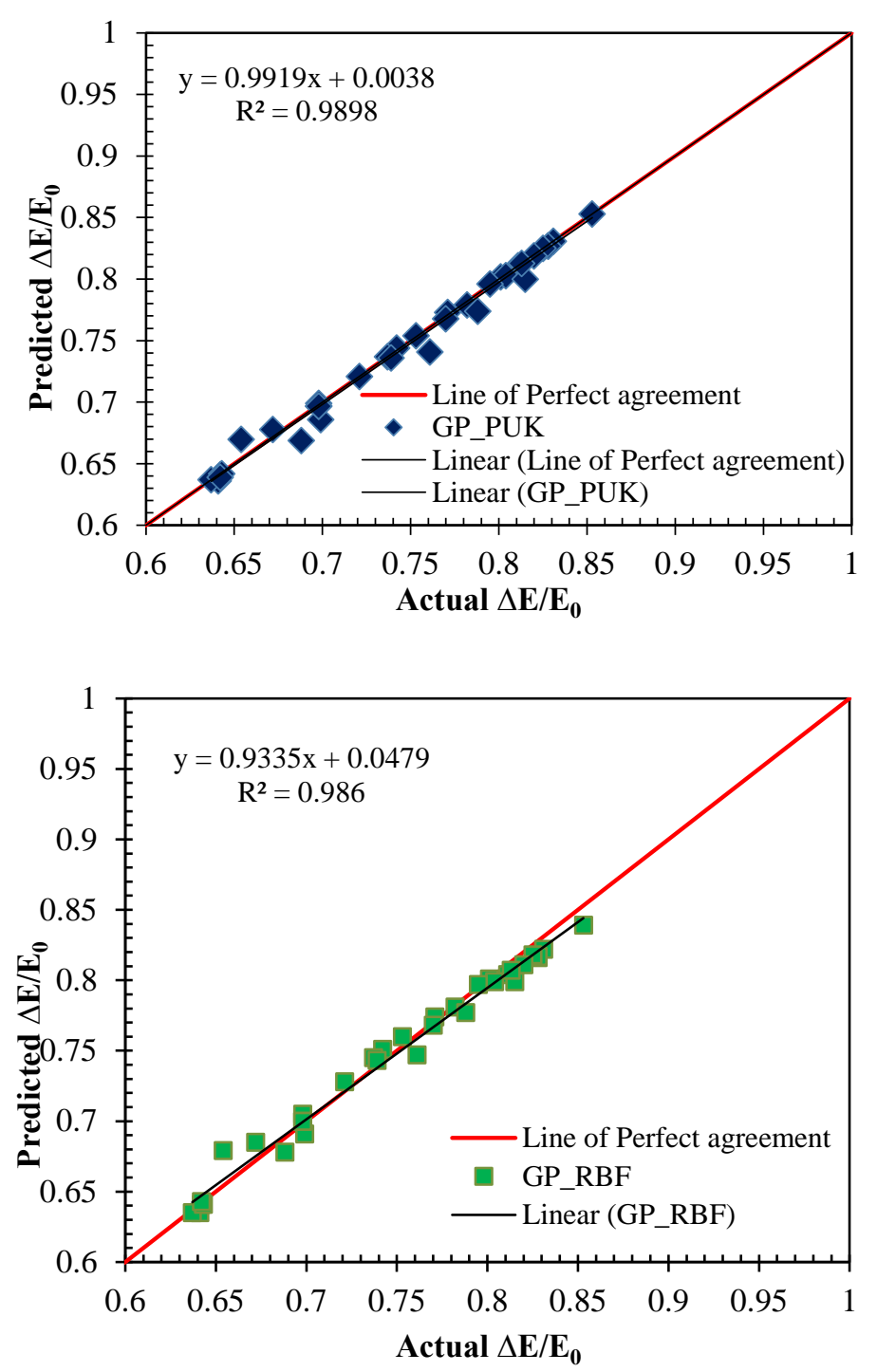

Figure 7. Comparison of actual and predicted values of $\Delta \mathrm{E} / \mathrm{E}_{0}$ using testing data with (a)

$$
\text { GP_PUK (b) GP_RBF }
$$

Preparation of a Support Vector Machine based model is an iteration method. A Pearson VII kernel function and radial basis kernel functions are used for the model preparation. The performance of SVM_PUK and SVM_RBF models are listed in Table 4. The results suggest that the model SVM_PUK model outperforms the SVM_RBF model. The SVM_Puk model for predicting $\triangle E / E_{0}$ result in $C C=0.9950, \mathrm{MAE}=0.0043$ and $\mathrm{RMSE}=0.0072$ for the testing stage. Results of SVM_PUK and SVM_RBF models are plotted in Fig. 8. 

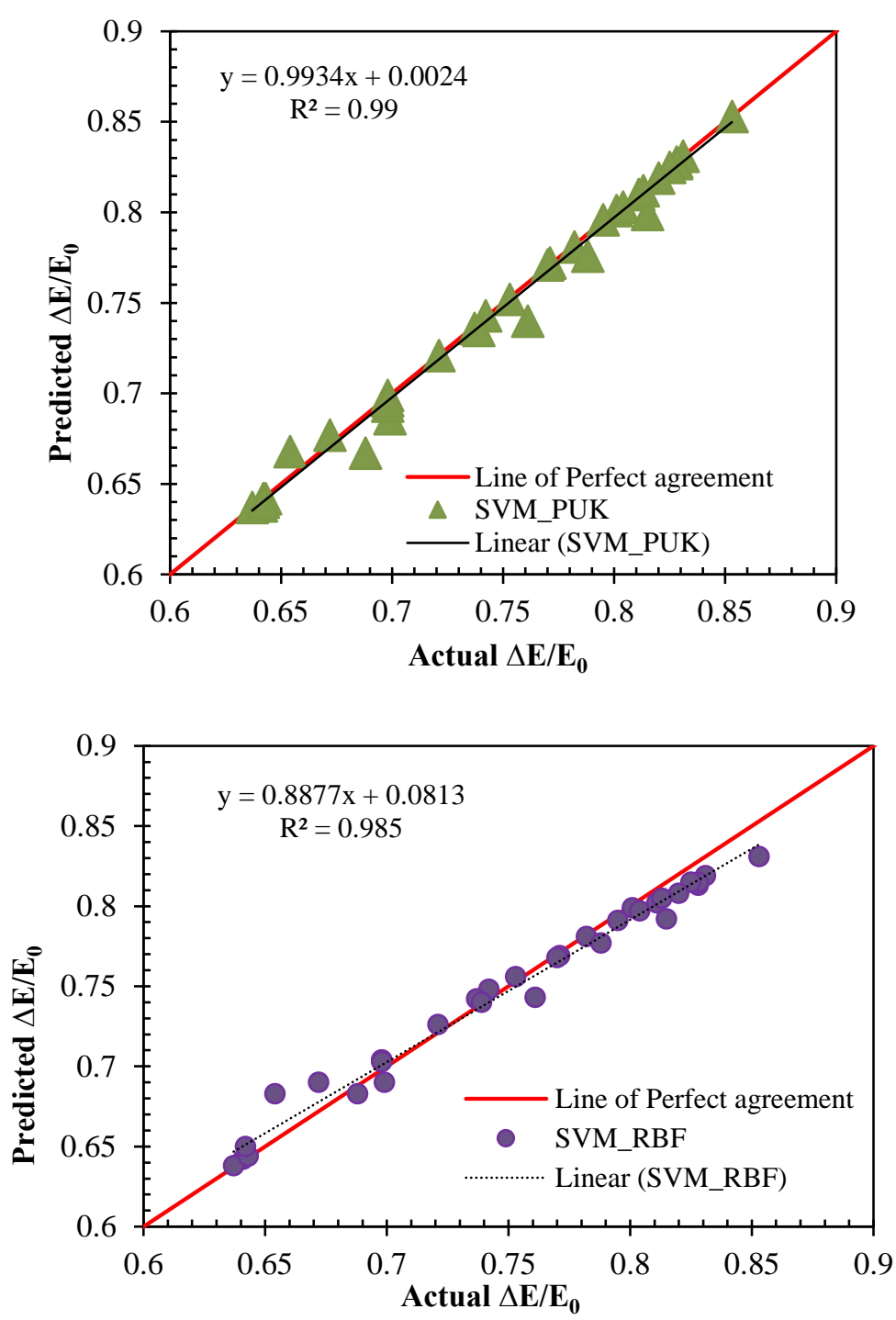

Figure 8. Comparison of actual and predicted values of $\Delta \mathrm{E} / \mathrm{E}_{0}$ using the testing dataset (a)

$$
\text { SVM_PUK (b) SVM_RBF }
$$

The preparation of a neural network-based model is also an iteration method. The performance of ANN and GRNN models are listed in Table 4. The results suggest that the model ANN model outperforms the GRNN model. The performance evaluation parameters for the GRNN based model the prediction of $\triangle E / E_{0}$ are: $\mathrm{CC}=0.9944, \mathrm{MAE}=0.0047$ and $\mathrm{RMSE}=0.0076$. Results of $\mathrm{ANN}$ and GRNN models during the testing stage are plotted in Fig. 9. 

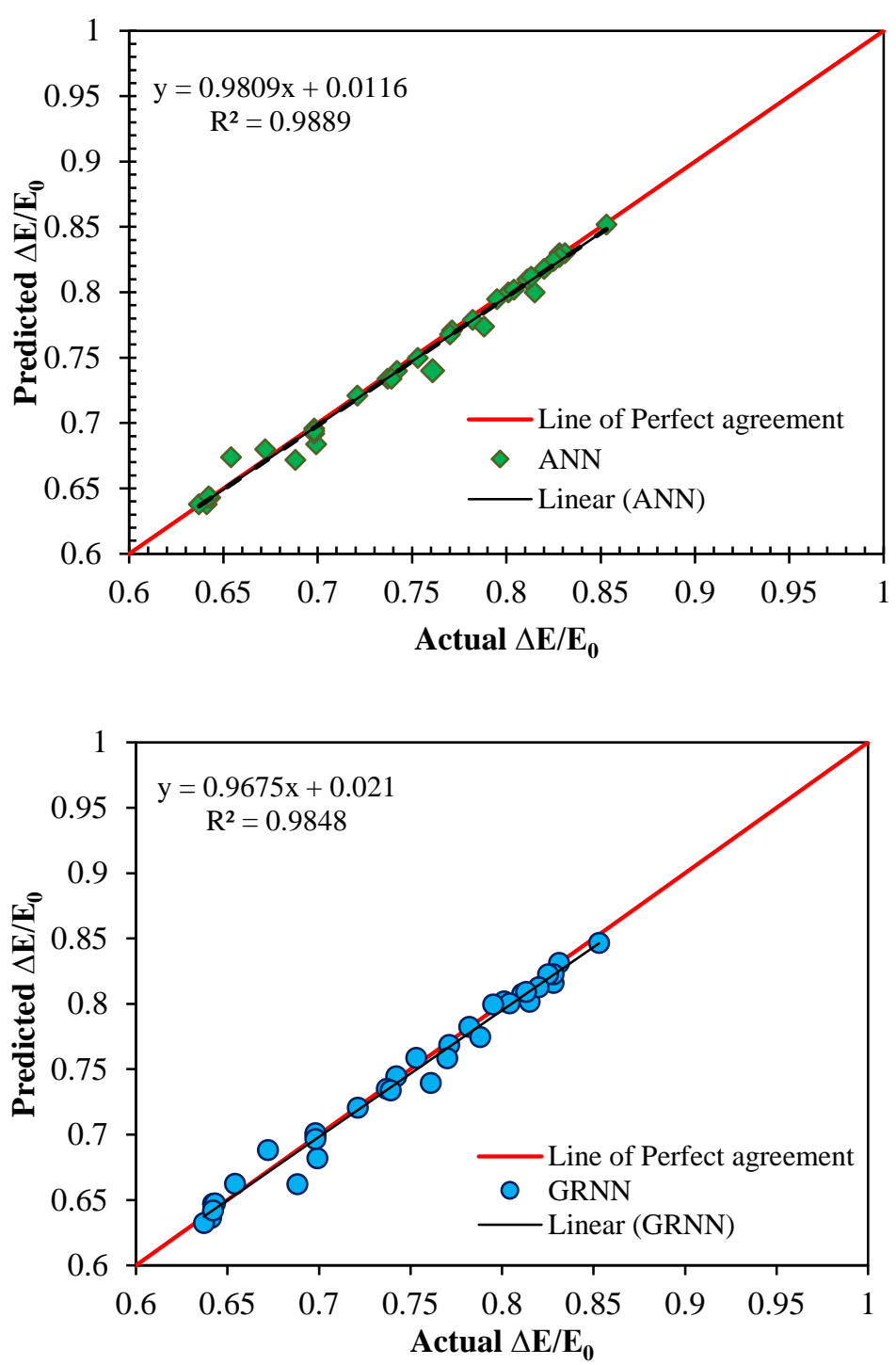

Figure 9. Comparison of actual and predicted values of $\triangle \mathrm{E} / \mathrm{E} 0$ using testing data (a) $\mathrm{ANN}$ (b)

\section{GRNN}

As with other cases, the preparation of ANFIS based model is also an iteration method. Four different types of membership functions (Triangular, Trapezoidal, Gaussian and Generalized bell shape) were used in this study. The performance of various ANFIS based models is listed in Table 4 and the results suggest that the Generalized bell shape-based ANFIS model (ANFIS_gbellmf) outperforms the other ANFIS based models. Performance evaluation parameters for the ANFIS_gbellmf model for the prediction of $\triangle E / E 0$ are: $\mathrm{CC}=0.9953, \mathrm{MAE}=0.0042$ and $\mathrm{RMSE}=0.0069$. Results of ANFIS based models during the testing stage are plotted in Fig. 10. 

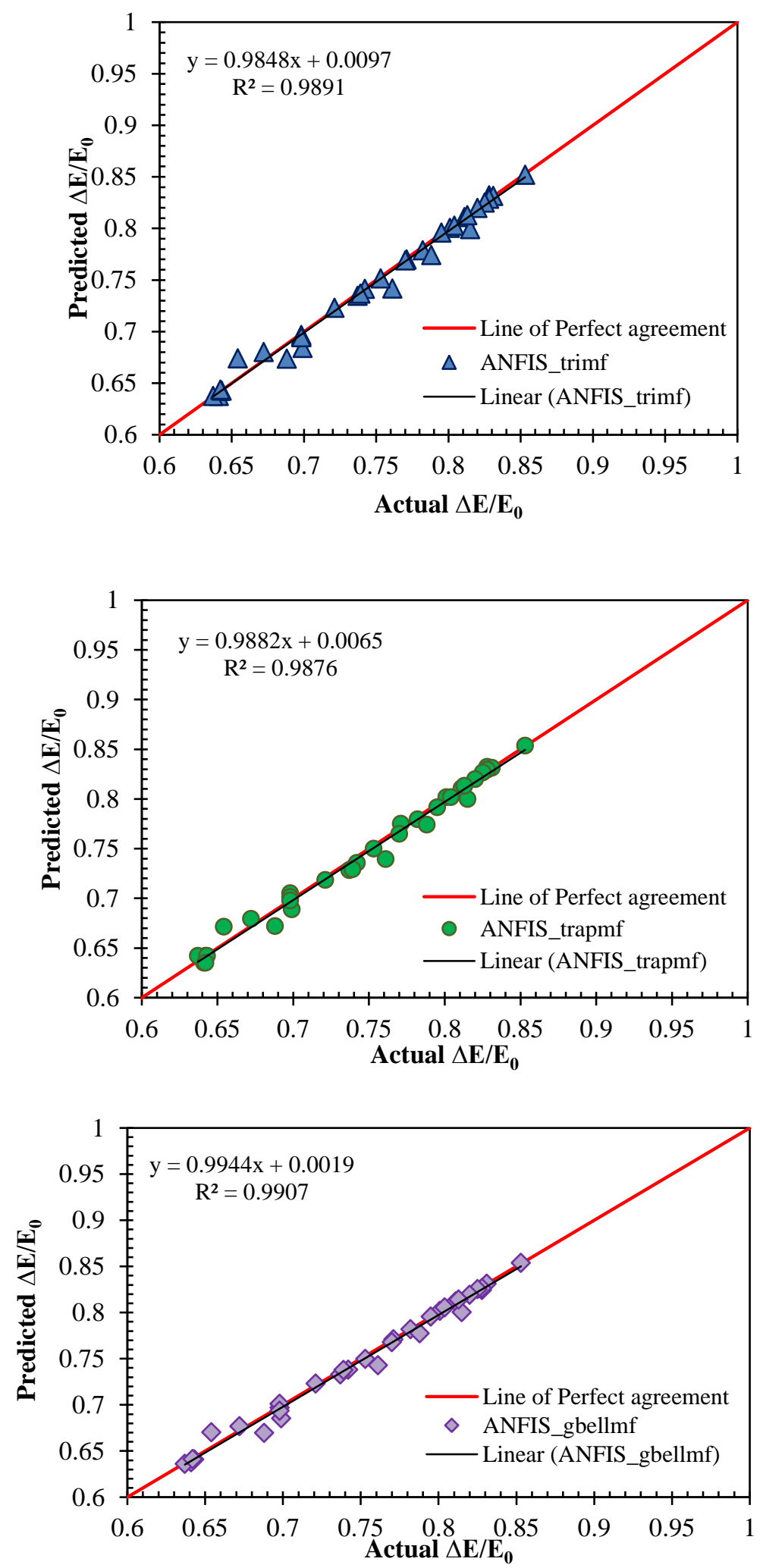


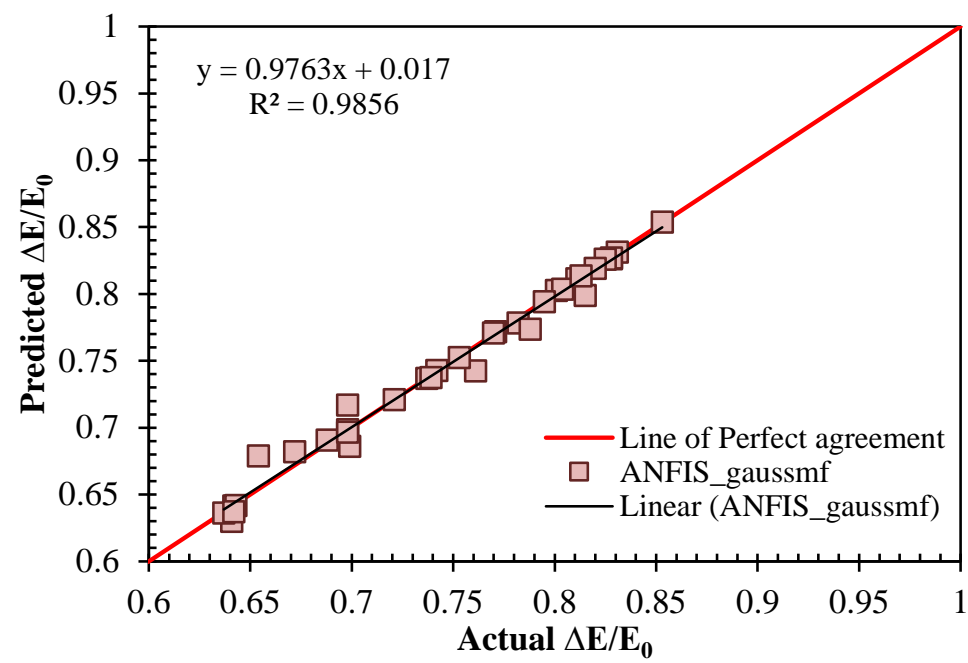

Figure 10. Comparison of actual and predicted values of $\Delta \mathrm{E} / \mathrm{E} 0$ using ANFIS based models

Comprehensive comparison among regression and soft-computing-based models (Table 6) suggests that the ANFIS_gbellmf based model performs better than the others. The linear regression model is superior to the MLR model for this dataset. Table 4 suggests that the GP model works better than SVM-based models for predicting $\Delta E / E_{0}$. A Pearson VII kernel function performs better than the radial basis kernel function with GP and SVM techniques. The ANN model outperforms the GRNN model. The results listed in Table 4 indicate that ANFIS_gbellmf is superior to other membershipbased ANFIS and other applied models. Single-factor ANOVA results are listed in Table 5. Table 4 suggests that there is no significant difference among actual and predicted values using the various models. Box plot (Fig. 11) was plotted where the overall error distribution is shown. As a result, the negative and positive error values correspond to over-estimation and under-estimation from the models, respectively. The values of minimum error, first quartile, median, mean, third quartile, and maximum error are listed in Table 6 and displayed in Fig. 11 for all applied models. As can be seen, the maximum and minimum errors from the ANFIS_gbellmf model are -0.0163 and 0.0185 , respectively, which verifies the capability of ANFIS_gbellmf to predict the $\Delta E / E_{0}$. Figure 11 shows results from the ANFIS_gbellmf based model. Figure 12 presents Taylor's diagram for all applied models; Taylor's diagram was used to illustrate the performance of the applied models. The three statistic parameters standard deviation, correlation, and root mean square error, were evaluated and comparisons between the actual and predicted results are shown for the Baitarani River. Figure 12 suggests that the ANFIS_gbellmf model achieves a higher correlation with the minimum standard deviation. Taylor's diagram also confirms that the ANFIS_gbellmf model is superior to the other models.

Table 4. Performance evaluation parameters for all models and both training and testing datasets

\begin{tabular}{|c|c|c|c|c|c|c|}
\hline \multirow{2}{*}{ Models } & $\mathrm{CC}$ & RMSE & MAE & $\mathrm{CC}$ & RMSE & MAE \\
\hline & \multicolumn{3}{|c|}{ Training data set } & \multicolumn{3}{|c|}{ Testing data set } \\
\hline LR & 0.9939 & 0.0067 & 0.0047 & 0.9933 & 0.0083 & 0.0067 \\
\hline MLR & 0.9861 & 0.0101 & 0.0075 & 0.9850 & 0.0127 & 0.0099 \\
\hline GP_PUK & 0.9986 & 0.0032 & 0.0017 & 0.9949 & 0.0071 & 0.0040 \\
\hline GP_RBF & 0.9935 & 0.0077 & 0.0056 & 0.9930 & 0.0089 & 0.0071 \\
\hline SVM_PUK & 0.9983 & 0.0035 & 0.0013 & 0.9950 & 0.0072 & 0.0043 \\
\hline SVM_RBF & 0.9923 & 0.0100 & 0.0074 & 0.9925 & 0.0108 & 0.0083 \\
\hline ANN & 0.9977 & 0.0042 & 0.0025 & 0.9944 & 0.0076 & 0.0047 \\
\hline GRNN & 0.9990 & 0.0027 & 0.0016 & 0.9923 & 0.0090 & 0.0065 \\
\hline
\end{tabular}


Table 5. Single Factor ANOVA results

\begin{tabular}{cccccc}
\hline No & Source of Variation & F & P-value & F crit & $\begin{array}{c}\text { Variation among } \\
\text { groups }\end{array}$ \\
\hline 1 & Between Actual and LR & 0.028359 & 0.866783 & 3.986269 & Insignificant \\
2 & Between Actual and MLR & 0.003051 & 0.956115 & 3.986269 & Insignificant \\
3 & Between Actual and GP_PUK & 0.017902 & 0.89397 & 3.986269 & Insignificant \\
4 & Between Actual and GP_RBF & 0.013371 & 0.908295 & 3.986269 & Insignificant \\
5 & $\begin{array}{c}\text { Between Actual and } \\
\text { SVM_PUK }\end{array}$ & 0.022424 & 0.881422 & 3.986269 & Insignificant \\
6 & $\begin{array}{c}\text { Between Actual and } \\
\text { SVM_RBF }\end{array}$ & 0.027302 & 0.869265 & 3.986269 & Insignificant \\
7 & Between Actual and ANN & 0.026635 & 0.870859 & 3.986269 & Insignificant \\
8 & Between Actual and GRNN & 0.040323 & 0.841467 & 3.986269 & Insignificant \\
9 & $\begin{array}{c}\text { Between Actual and } \\
\text { ANFIS_trimf }\end{array}$ & 0.01097 & 0.9169 & 3.986269 & Insignificant \\
10 & $\begin{array}{c}\text { Between Actual and } \\
\text { ANFIS_trapmf }\end{array}$ & 0.019206 & 0.890199 & 3.986269 & Insignificant \\
11 & $\begin{array}{c}\text { Between Actual and } \\
\text { ANFIS_gbellmf }\end{array}$ & 0.019345 & 0.889806 & 3.986269 & Insignificant \\
12 & $\begin{array}{c}\text { Between Actual and } \\
\text { ANFIS_gaussmf }\end{array}$ & 0.001845 & 0.965868 & 3.986269 & Insignificant \\
\hline
\end{tabular}

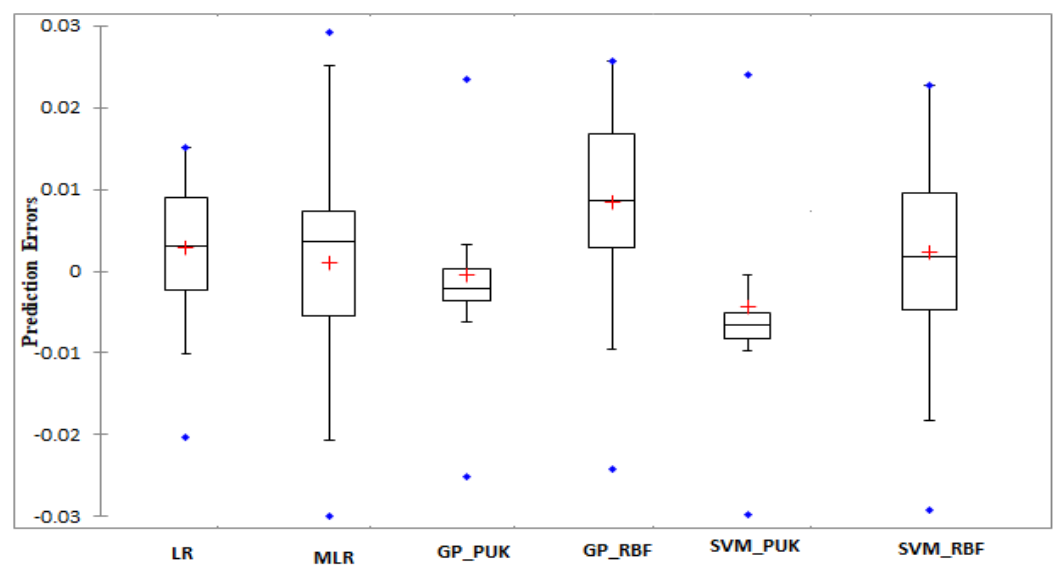

\begin{tabular}{cllllll} 
ANFIS_trimf & 0.9981 & 0.0038 & 0.0022 & 0.9946 & 0.0072 & 0.0042 \\
ANFIS_trapmf & 0.9979 & 0.0039 & 0.0027 & 0.9938 & 0.0078 & 0.0055 \\
ANFIS_gbellmf & $\mathbf{0 . 9 9 8 6}$ & $\mathbf{0 . 0 0 3 2}$ & $\mathbf{0 . 0 0 2 1}$ & $\mathbf{0 . 9 9 5 3}$ & $\mathbf{0 . 0 0 6 9}$ & $\mathbf{0 . 0 0 4 2}$ \\
ANFIS_gaussmf & 0.9986 & 0.0032 & 0.0019 & 0.9928 & 0.0081 & 0.0046 \\
\hline
\end{tabular}




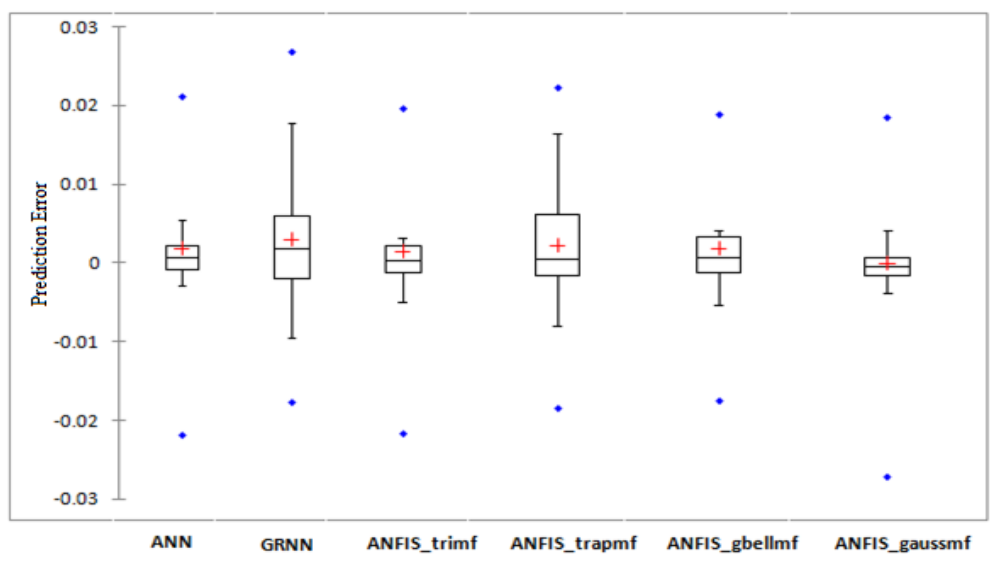

Figure 11. Box Plot of applied model error distribution using the test data set

Table 6. Error statistics for all applied models

\begin{tabular}{ccccccc}
\hline Statistic & LR & MLR & GP_PUK & GP_RBF & SVM_PUK & SVM_RBF \\
\hline Minimum & -0.0203 & -0.0296 & -0.0160 & -0.0250 & -0.0140 & -0.0290 \\
Maximum & 0.0151 & 0.0288 & 0.0200 & 0.0160 & 0.0210 & 0.0230 \\
1st Quartile & -0.0022 & -0.0055 & 0.0000 & -0.0028 & 0.0000 & -0.0045 \\
Median & 0.0031 & 0.0036 & 0.0010 & 0.0020 & 0.0010 & 0.0020 \\
3rd Quartile & 0.0090 & 0.0071 & 0.0028 & 0.0087 & 0.0020 & 0.0098 \\
Mean & 0.0028 & 0.0009 & 0.0022 & 0.0019 & 0.0025 & 0.0026 \\
\hline & ANN & GRNN & ANFIS_trimf & ANFIS_trapmf & ANFIS_gbellmf & ANFIS_gaussmf \\
\hline Minimum & -0.0200 & -0.0162 & -0.0201 & -0.0176 & -0.0163 & -0.0251 \\
Maximum & 0.0210 & 0.0259 & 0.0190 & 0.0215 & 0.0185 & 0.0183 \\
1st Quartile & 0.0007 & -0.0013 & -0.0007 & -0.0014 & -0.0007 & -0.0008 \\
Median & 0.0015 & 0.0023 & 0.0006 & 0.0005 & 0.0011 & 0.0003 \\
3rd Quartile & 0.0031 & 0.0061 & 0.0024 & 0.0061 & 0.0033 & 0.0014 \\
Mean & 0.0027 & 0.0033 & 0.0017 & 0.0023 & 0.0023 & 0.0007 \\
\hline
\end{tabular}



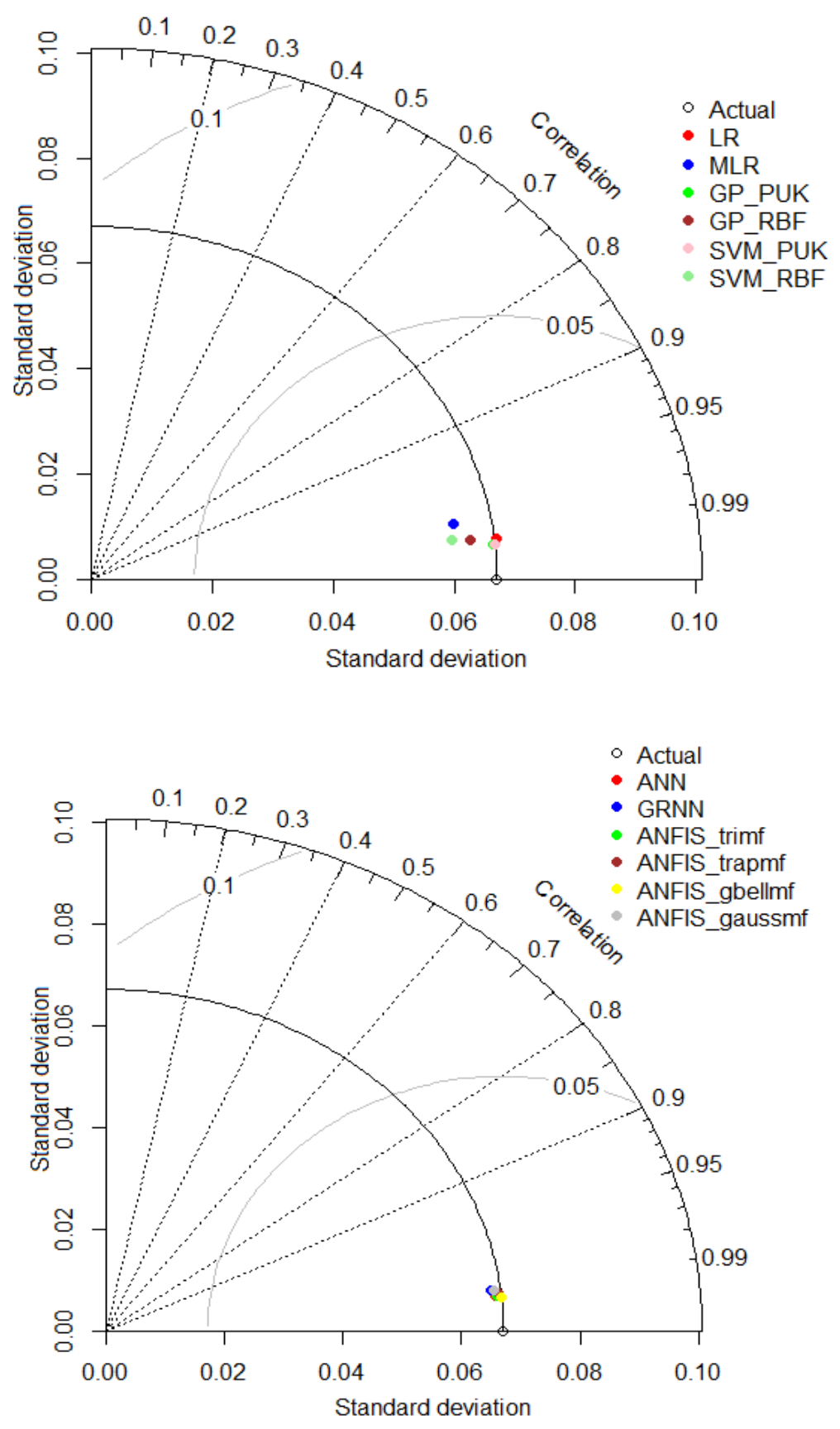

Figure 12. Taylor Diagram (a) LR, LR, GP \& SVM (b) ANN, GRNN \& ANFIS based models

\section{Sensitivity study}

A sensitivity study is used to determine the impact of each independent variable on the output. Numerous methods have been introduced to perform such a sensitivity study artificial intelligencebased models and the best performing model (ANFIS_gbellmf) was used to assess sensitivity. The models are prepared by removing one input parameter from the input combination of the bestdeveloped model. The performance of each model in the absence of one of the inputs was assessed and listed in Table 7. The results show that $y_{c} / h$ is the most effective parameter for predicting $\triangle E / E_{0}$. 
Table 7. Sensitivity investigation based on the ANFIS_gbellmf model

\begin{tabular}{|c|c|c|c|c|c|c|c|}
\hline \multirow{2}{*}{ No } & \multicolumn{3}{|c|}{ Input combination } & \multirow{2}{*}{$\frac{\text { Output }}{\Delta \mathrm{E} / \mathrm{E}_{0}}$} & \multicolumn{3}{|c|}{ ANFIS_gbellmf } \\
\hline & $\mathrm{y}_{\mathrm{c}} / \mathrm{h}$ & $\mathrm{yd}_{\mathrm{d}} / \mathbf{y}_{\mathrm{c}}$ & $\mathbf{p}$ & & $\mathrm{CC}$ & RMSE & MAE \\
\hline 1 & & & & & 0.9953 & 0.0069 & 0.0042 \\
\hline 2 & & & & & 0.9933 & 0.0082 & 0.0054 \\
\hline 3 & & & & & 0.9930 & 0.0082 & 0.0056 \\
\hline 4 & & & & & 0.9910 & 0.0098 & 0.0076 \\
\hline
\end{tabular}

\section{Conclusions}

This study assessed the performance of regression and soft-computing-based models for predicting $\Delta E / E_{0}$. The performance of all respective models remained satisfactory during the training and testing stages. The performance of the ANFIS_gbellmf based model is better than other models and has a higher correlation coefficient and a minimum of mean absolute error and root mean square error. A linear regression model is superior to MLR based models. Another observation is that the GP model works better than SVM-based models. A Pearson VII kernel function performs better than a radial basis kernel function with GP and SVM techniques. The ANN model outperforms the GRNN model. A sensitivity investigation reveals that $y_{c} / h$ is the most effective parameter for predicting the $\triangle E / E_{0}$ using ANFIS_gbellmf based model.

Author Contributions: R.N; analyzed experimental results and wrote the paper, P.S.; used the predictor models and analyzed their results, R.D; carried out experiments and contributed in the results analysis, J.A; reviewed and revised the paper and also contributed to the models' results analysis. All authors have read and agreed to the published version of the manuscript.

Funding: This research received no external funding.

Conflicts of Interest: The authors declare no conflict of interest.

\section{References}

1. Rajaratnam, N.; Hurtig, K. Screen-type energy dissipator for hydraulic structures. Journal of Hydraulic Engineering. 2000, 126(4), 310-312.

2. Rajaratnam, N.; Hurtig, K.I. Screen-type energy dissipator for hydraulic structures. Journal of Hydraulic Engineering. 2000, 126(4), 310-312.

3. Chamani, M.R.; Rajaratnam, N.; Beirami, M.K. Turbulent jet energy dissipation at vertical drops. Journal of hydraulic engineering. 2008, 134(10), 1532-1535.

4. Kabiri-Samani, A.R.; Bakhshian, E.; Chamani, M.R. Flow characteristics of grid drop-type dissipators. Flow Measurement and Instrumentation. 2017, 54, 298-306.

5. Daneshfaraz, R.; Majedi Asl, M.; Bazyar, A.; Abraham, J.; Norouzi, R. The laboratory study of energy dissipation in inclined drops equipped with a screen. Journal of Applied Water Engineering and Research. 2020, 1-10. Available from https://doi.org/10.1080/23249676.2020.1799877. DOI 10.1080/23249676.2020.1799877. 
6. Rouse, H. Discharge characteristics of the free overfall: Use of crest section as a control provides easy means of measuring discharge. Civil Engineering. 1936, 6(4), 257-260.

7. Chamani, M.; Beirami, M.K. Flow characteristics at drops. Journal of Hydraulic Engineering. 2002, 128(8), 788-791.

8. Balkiş, G., 2004. Experimental investigation of energy dissipation through inclined screens. M. Sc. Thesis, Department of Civil Engineering Middle East Technical ....

9. Esen, I.I.; Alhumoud, J.M.; Hannan, K.A. Energy loss at a drop structure with a step at the base. Water international. 2004, 29(4), 523-529.

10. Hong, Y.M.; Huang, H.S.; Wan, S. Drop characteristics of free-falling nappe for aerated straight-drop spillway. Journal of Hydraulic Research. 2010, 48(1), 125-129.

11. Sadeghfam, S.; Akhtari, A.A.; Daneshfaraz, R.; Tayfur, G. Experimental investigation of screens as energy dissipaters in submerged hydraulic jump. Turkish Journal of Engineering and Environmental Sciences. 2015, 38(2), 126-138.

12. Daneshfaraz, R.; Sadeghfam, S.; Ghahramanzadeh, A. Three-dimensional numerical investigation of flow through screens as energy dissipators. Canadian Journal of Civil Engineering. 2017, 44(10), 850-859.

13. Sharif, M.; Kabiri-Samani, A. Flow regimes at grid drop-type dissipators caused by changes in tail-water depth. Journal of Hydraulic Research. 2018, 1-12.

14. Daneshfaraz, R.; Sadeghfam, S.; Hasanniya, V. Experimental investigation of energy dissipation in vertical drops equipped with a horizontal screen under supercritical flow. Iranian Journal of Soil and Water. 2019, 50(6), 1421-1436. DOI 10.22059/IJSWR.2019.269301.668053.

15. Daneshfaraz, R.; Majedi Asl, M.; Razmi, S.; Norouzi, R.; Abraham, J. Experimental investigation of the effect of dual horizontal screens on the hydraulic performance of a vertical drop. International Journal of Environmental Science and Technology. 2020. Available from https://doi.org/10.1007/s13762-01902622-x. DOI 10.1007/s13762-019-02622-x.

16. Norouzi, R.; Daneshfaraz, R.; Bazyar, A. The study of energy depreciation due to the use of vertical screen in the downstream of inclined drops by adaptive neuro-fuzzy inference system (anfis). AUT Journal of Civil Engineering. 2019. DOI 10.22060/CEEJ.2019.16694.6305.

17. Sadeghfam, S.; Daneshfaraz, R.; Khatibi, R.; Minaei, O. Experimental studies on scour of supercritical flow jets in upstream of screens and modelling scouring dimensions using artificial intelligence to combine multiple models (aimm). Journal of Hydroinformatics. 2019, 21(5), 893-907.

18. Bakhmeteff, M.W., 1932. Hydraulics of open channels. New York and London: McGraw-Hill book company, Inc.

19. Grant, D.; Dawson, B., 2001. Isco open channel flow measurement handbook. Lincoln, neb.: Isco. Inc.

20. Çakir, P., 2003. Experimental investigation of energy dissipation through screens. Citeseer.

21. Haykin, S. Neural networks: A comprehensive foundation. 1999. Mc Millan, New Jersey. 2010, 1-24.

22. Salmasi, F.; Yıldırım, G.; Masoodi, A.; Parsamehr, P. Predicting discharge coefficient of compound broad-crested weir by using genetic programming (gp) and artificial neural network (ann) techniques. Arabian Journal of Geosciences. 2013, 6(7), 2709-2717. Available from https://doi.org/10.1007/s12517012-0540-7. DOI 10.1007/s12517-012-0540-7.

23. Malik, A.; Kumar, A.; Kim, S.; Kashani, M.; Khosrowshahi, V.; Sharafati, A.; Ghorbani, M.A.; Al-Ansari, N.; Salih, S.; Yaseen, Z.; Chau, K.-W. Modeling monthly pan evaporation process over the indian central himalayas: Application of multiple learning artificial intelligence model. Engineering Applications of Computational Fluid Mechanics. 2020, 14. DOI 10.1080/19942060.2020.1715845. 
24. Nou, M.; Azhdary, M.; Bajestan, M.; Azamathulla, H. Estimation of scour depth around submerged weirs using self-adaptive extreme learning machine. Journal of Hydroinformatics. 2019. DOI 10.2166/hydro.2019.070.

25. Bilhan, O.; Kisi, O.; Emiroglu, M. Anfis to estimate discharge capacity of rectangular side weir. Proceedings of the ICE - Water Management. 2013, 166, 479-487. DOI 10.1680/wama.11.00095.

26. Shamshirband, S.; Bonakdari, H.; Zaji, A.; Petkovic, D. Improved side weir discharge coefficient modeling by adaptive neuro-fuzzy methodology. KSCE Journal of Civil Engineering. 2015, 20. DOI 10.1007/s12205-016-1723-7.

27. Vapnik, V.N. T he nature of statistical 1 earning t heory. New York: Springer2V erlag. 1995.

28. Vapnik, V., 2013. The nature of statistical learning theory. Springer science \& business media.

29. Zaji, A.; Bonakdari, H.; Shamshirband, S. Support vector regression for modified oblique side weirs discharge coefficient prediction. Flow Measurement and Instrumentation. 2016, 51. DOI 10.1016/j.flowmeasinst.2016.08.006.

30. Roushangar, K.; Alami, M.; Shiri, J.; Majedi Asl, M. Determining discharge coefficient of labyrinth and arced labyrinth weirs using support vector machine. Hydrology Research. 2017, 49, nh2017214. DOI 10.2166/nh.2017.214.

31. Norouzi, R.; Daneshfaraz, R.; Ghaderi, A. Investigation of discharge coefficient of trapezoidal labyrinth weirs using artificial neural networks and support vector machines. Applied Water Science. 2019, 9(7), 148. Available from https://doi.org/10.1007/s13201-019-1026-5. DOI 10.1007/s13201-019-1026-5.

32. Grbic, R.; Kurtagić, D.; Slišković, D. Stream water temperature prediction based on gaussian process regression. Expert Systems with Applications. 2013, 40, 7407-7414. DOI 10.1016/j.eswa.2013.06.077.

33. Mihoub, R.; Nabil, C.; Guermoui, M. Modeling soil temperature based on gaussian process regression in a semi-arid-climate, case study ghardaia, algeria. Geomechanics and Geophysics for Geo-Energy and Geo-Resources. 2016, 2. DOI 10.1007/s40948-016-0033-3.

34. Akbari, M.; Salmasi, F.; Arvanaghi, H.; Karbasi, M.; Farsadizadeh, D. Application of gaussian process regression model to predict discharge coefficient of gated piano key weir. Water Resources Management. 2019, 1-19. DOI 10.1007/s11269-019-02343-3.

35. Prabakaran, S.; Kumar, P.N.; Tarun, P.S.M. Rainfall prediction using modified linear regression. ARPN Journal of Engineering and Applied Sciences. 2017, 12(12), 3715-3718.

36. Emiroglu, M.E.; Kisi, O. Prediction of discharge coefficient for trapezoidal labyrinth side weir using a neuro-fuzzy approach. Water Resources Management. 2013, 27(5), 1473-1488. Available from https://doi.org/10.1007/s11269-012-0249-0.

37. Shirgure, P. Evaporation modeling with multiple linear regression techniques-a review. Scientific Journal of Review. 2012, 1(6), 170.

38. Ghorbani, M.A.; Khatibi, R.; Hosseini, B.; Bilgili, M. Relative importance of parameters affecting wind speed prediction using artificial neural networks. Theoretical and Applied Climatology. 2013, 114. DOI 10.1007/s00704-012-0821-9.

39. Nouri, M.; Sihag, P.; Salmasi, F.; Kisi, O. Energy loss in skimming flow over cascade spillways: Comparison of artificial intelligence-based and regression methods. Applied Sciences. 2020. DOI 10.3390/app10196903. 